\title{
ONS TAALERFENIS.
}

Dit is byna onvermydelik wanneer ons die waarde van Afrikaans as volkstaal, moedertaal of selfs as kultuurtaal probeer bepaal, dat ons dit doen in terme van die geskiedenis en die nasionale waarde van die stryd wat gevoer moes word om die erkenning, gebruik en behoud daarvan. Temeer is dit die geval omdat die stryd vandag nog nie volstry is nie, en omdat daar vandag nog in groot mate taalversaking en taalverwaarlosing is, ondanks alles wat verkry en bereik is. Die stryd is dikwels negatief gevoer teen Engels as bevoorregte taal, omdat die bevoorregting en begunstiging daarvan bereken en bedoel was om die Hollands-Afrikanse volksdeel te angliseer. So was die stryd om taalbehoud meteen en veral die worsteling om nasionale selfbehoud. En hiervoor was noodsaaklik die behoud en versterking van die afstammingsverband van die Afrikaner.

Aanvanklik gevoer in die twintiger-dertiger jare van die vorige eeu in die vorm van verset en protes teen die verbanning van Nederlands as medium van landsbestuur en gereg het die stryd om taalbehoud hom allengs aktief moes uitbrai ook ina die gebiede van onderwys en kerk, toe die angliseringspolitiek ook daar toegepas word. Want dit is duidelik besef geword dat met die verlies van die taal ook verlore sal raak alles wat in en deur die taal gedra en gekarakteriseer word: nasionale identi- 
teit, lewenshouding, lewenstyl, lewensvorm en lewensinhoud; kultuur, godsdiensvorm en grootliks die inhoud daarvan. Taalverlies sou beteken die omskepping van die hier-geworde en hier-ontstane nasie van Hollands-Afrikaanse tipe en karakter tot iets wat nasionaal, kultureel en religieus iets anders sou wees. Dit alles sou dus beteken die verbreking van die Nederlandse afstammingsverband, van die tradisie en die geestesband met die beskawings- en kultuurverlede waaruit die Afrikaner histories ontstaan en gegroei het en waaruit hy besieling en boumateriaal vir die toekoms vir sy eie-aard moes put. Die verset, protes en stryd teen die beleid van verdringing van „Hooghollands” of Nederlands deur die Engelse Bewind uit die staat, die skool en die kerk was in werklikheid 'n bewuste aksie tot behoud van die Nederlandse erfenis wat Jan van Riebeeck na die Kaap gebring en aan die end van sy kommandeurskap hier gevestig gelaat het vir verdere groei en verryking op eie bodem in eie atmosfeer. Dit het gebeur in die proses van historiese wording en uitbouing deur saamgroeiing van verskillende volkselemente, Nederlanders, Franse en Duitsers, by die ontplooiing en ontvouing van God se bouplan vir Suidelike Afrika.

As nou in die sewentiger jare die stryd die vorm aanneem van 'n stryd vir Afrikaans i.p.v. Hooghollands en vir die hier-geworde spesifiek Afrikaanse lewensvorm en lewensinhoud, dan is dit nie 'n stryd teen Hollands en die Hollandse kultuur en tradisie nie maar, inteendeel, juis omdat daardeur alleen die tradisie behou kon word, en die Nederlandse beskouing en kultuur in sy hele omvang en ryke verskeidenheid 'n blywende voedingsbron kon bly vir wat daaruit in die nuwe land tot 'n nuwe selfstandigheid ontwikkel het: dit was die volledige, klinkende erkenning en aanvaarding van die Hollandse erfenis op alle terreine van die lewe. Die stryd vir Afrikaans was 'n stryd on lewe en dood vir die die behoud van die afstammingsverband as 'n noodsaaklikheid vir bestaan, groei en verrykende ontwikkeling van die nasie-eenheid wat „,in den bloede", in beskawings- en kultuurvorm, in geloofs- en lewensvorm en ten opsigte van nasionaal-vrye en staatlik-selfstandige aspirasies van sewentiende-eeuse Hollandse herkoms is.

By die driehonderdjarige herdenking van die volksplanting aan die Kaap is dit dus gepas om ons rekenskap te gee van wat ons taalerfenis en die waarde daarvan is. Te maklik sal die taak nie wees nie, omdat dit vir ons hier te lande, geografies so ver van Nederland geleë, en staatkundig, selfs ook kultureel reeds, so los daarvan en so ingekerker in die moderne tydskompleks, skaars moontlik is om ons ten volle in te lewe in die toentertydse Nederlandse volksgees en daardie tydsverband en ons 'n denkbeeld te vorm of grondige besef te kry van die daadkrag, 
ondernemingsgees en geloofsmoed wat daardie volk waaruit ons gegroei het, help vorm en laat triomfeer het oor alle weerstand op sy pad na die skitterende hoogtes van staatlike en nasionale selfstandigheid, van beskawing en kultuur, vryheid van denke en daad, gewetens- en geloofsvryheid, maar steeds met behoud van die bewustheid van onderworpenheid aan en afhanklikheid van Hom wat hy in geloof aanvaar, aanbid, verheerlik en verdedig het. Die geestesmagte wat so sterk en intens die gemoedere van die Nederlanders en veral van die leidende figure geroer en rigting gegee het, het hulle blywende neerslag gevind in die spesifiekNederlandse gees, beskawingsvorm en lewenstyl van die tyd soos beliggaam in die kunste en wetenskap, die staatkunde en religie en nie minder in die praktiese sin, ondernemingsgees en deursettingsvermoë van handel, skeepvaart en langdurige vryheidstryd nie. Daarom het die eeu geword die Goue Eeu, die eeu van Willem van Oranje, van Grotius, van Rembrandt, van Vondel, van Dordt, van die Statebybel en van ... Jan van Riebeen!

As ons nou in ag neem dat taal die middel is waardeur en waarin die indiwidu en, deur die gesamelikheid van die indiwidue, die volksgemeenskap die geestesbesit vorm en vergestalt, dan is dit begryplik dat die Nederlandse taalvorm van die tyd die primêre middel geword het wat die geestesrykdom van die sewentiende-eeuse Nederland moes beliggaam en dra en dat die taalvorm weer die primêre en direkte middel is om toegang te kry tot daardie rykdom in sy volle en ware wese. Per slot van rekening is die waarde van alle kunste, wetenskap. kultuur, beskawing en religie bepaalbaar in terme van ons vermoë om hulle deur en in taal te interpreteer, verstaanbaar en waardeerbaar te maak. En dis dié taalvorm met $s y$ inhoud en die omvang daarvan wat Jan van Riebeeck ons as erfenis nagelaat het in die skryfvorm van dic tyd, maar ook in Afrikaans soos dit ontwikkel het uit die Hollands-dialektiese spreektaal van die Koloniste aan die Kaap.

Die waarde en betekenis van hierdie erfenis moet ons aldus bepaal: ons het nie grond om aan te neem dat Jan van Riebeeck iets meer en iets anders was nie as ' $n$ dienaar en amptenaar van die winsbejaende V.O.I.C. wat vir die beroep van skeepsdokter 'n goeie en selfs deeglike opleiding gehad het. Uit sy nagelate skryfprodukte, met name die Dagverhaal, blyk dat hy Nederlands in die skryfvorm van sy tyd redelik goed beheers het, soos mens trouens van so'n amptenaar met sy ervaring kon verwag. Maar ons het min grond om aan te neem dat die volksplanter 'n besondere of ook maar slegs 'n kenner was van die literêre produkte van sy tydgenote, Hooft, Vondel, Huygens of selfs maar 
Bredero, of van die skilderkuns van sy tyd en van vroeër-al het ons geskilderde portrette van hom en van Maria de Quellerie-of dat hy besonder onderlê was in die akademiese wêreld, in die staatkunde en ewemin in die gereformeerde teologie of geloofsleer. Maar wat ons wel in Van Riebeeck moet sien, is 'n verteenwoordiger en draer van die Nederlandse gees van die tyd waarin en waardeur hy self gevorm is, 'n draer van de lewensvorm en lewenstyl van die Nederlandse beskawing en kultuur, 'n belyer van die „ware gereformeerde Christelijcke Lere" en 'n praktiese vertolker en handhawer daarvan. In die Goue Eeu is hy gebore, feitlik binne die kring van die grootste aktiwiteit; sy jeug het geval in die tyd van grootste kragsontplooiing en hoogste bloei; in die jare van grootste triomf op alle gebiede het sy jongelingskap geryp; hy is gevorm en opgevoed in die skool van die praktiese lewe, bepaal deur 'n onvergelyklike ondernemingrgees. Sy deelname hieraan juis op die terrein van die handel ter see met die Nederlandse wingeweste en die buiteland in diens van die handelsmaatskappye het hom intensief met die belangrikste aktiwiteite in die volkslewe in in die staatsbestuur, met die sterkste en omvattendste aspirasies van die Nederlandse volk op alle gebied, direk en indirek, in aanraking gebring. Allesins het ons in Jan van Riebeeck 'n selek eksemplaar van die sewentiende-eeuse praktiese, nugtere maar ook geestelik sterk en oortuigde Nederlander, draer en verteenwoordiger van alles wat Nederland self gelewer het aan die onverganklike dinge van gees en verstand, van hoof en hart en hand, van geloof en daad, van besinning en skepping, van bepaling en vestiging van die beginselsewigheidsbeginsels-wat die lewe van die mens maatskaplik, staatlik, na:-ionaal, geestelik-kultureel, en kerklik moet beheers en vorm gee. En dis juis hierdie lewensvorm en lewensinhoud wat Jan van Riebeeck na die Cabo de Bona Espérance oorgebring, hier gevestig en beskerm het: ons volkstamlike erfenis, gebring en gedra in en deur die Nederlandse taalvorm uit sy mond en die van sy amptenare en die Koloniste, die skriftelike taalvorm ook van sy Dagverhaal, van die Statebybel, die gereformeerde liturgie, van die Berymde Psalme en van sy Gebed.

Dit is uit hierdie tweevormige taalerfenis: die volkstaal in die volksmond en die skryf- of literatuurtaal dat Afrikaans ontstaan en ontwikkel het. Dis nie die plek hier om op die vraagstuk van die ontstaan en wording in te gaan nie, maar tog is dit nodig om hierdie aspek duidelik te stel, nl. die ontwikkeling van Afrikaans uit die volkstaal van die sewentiende eeu onder die rigtende, beskermende, regulerende en vormende invloed van die skryftaal wat ook die taal van die Statebybel, die kerktaal, die onderwystaal, die leestaal en die taal van die landsbestuur was. 
Die ontstaansproses van Afrikaans het in Dietse taalwetenskaplike kringe al veel aandag geniet, en teorieë wat die ontstaan moet verklaar, is vanuit verskillende gesigspunte gestel. Namate meer gegewens en resultate van navorsing beskikbaar kom deur historiese en vergelykende studie, veral op die gebied van die vergelykende dialektologie, word die beeld van die ontstaansproses en die ontwikkelingsgang duideliker. Hierdie wetenskaplike vordering het vergoed afgedoen met die Hottentotteorie, met die hardnekkige Maleis-Portugees-teorie en met die Fransteorie. Al kon die spontane ontwikkelingsteorie vanweë die invloed wat nie-Nederlandssprekende elemente direk deur hulle eie taal of deur hulle krom-Nederlands op die woordeskat en wording van Afrikaans gehad het, ewemin volgehou word, dan word tog erken dat hierdic invloede nie die ontstaan van Afrikaans veroorsaak het nie, ook nie die Nederlandse taal in sy Germaans-Dietse wese verander het in die ontwikkeling tot Afrikaans nie, maar dat Afrikaans, in wese deur-en-deur 'n Germaans-Dietse taal, slegs 'n vereenvoudigde vorm van Nederlands gebly het. Invloed van vreemde sprekers in groot getal-Hottentotte, Oosterse en Afrikaanse slawe, Franse en Duitsers, - het beslis bygedra tot gelykmaking van taalverskille deur ,dialekmenging" (verskillende kromtaalvorme ingesluit), tot aanvulling en verandering van die woordeskat en veral tot versnelling van die vereenvoudigings- en gelykmakingsproses van deflektering en daarmee van die wording van 'n spesifiekAfrikaanse sintaksis en struktuur; die vermenging van verskillende uitspraaksubstrata of artikulasiebasisse en moontlik die spel van erflikheidsfaktore deur bloedmenging het die spesifiek-Afrikaanse artikulasiebasis laat ontwikkel wat belangrike artikulatoriese en akoestiese konsekwensies t.o.v. die klankstelsel meegebring het, en, aangehelp deur klimaatsen omgewingsinvloede, die Afrikaanse klankstelsel en struktuur in 'n mate van die Nederlandse of Hollandse laat afwyk het. By die aanpassing van die Hollandse woordeskat in die nuwe vaderland is leemtes en behoeftes waarin nie deur die natuurlike taalmiddels soos nutskepping, afleiding, samestelling, analogie e.s.m. voorsien kon word nie, aangevul deur ontleninge uit die autochthone inboorlingtale, Hottentots en eers later die Bantoetale, uit die ingevoerde taalvorme van die Afrikaanse en Oosterse slawe en die kreoolse Maleis-Portugees. So gering is hierdie ontleninge in aantal en linguïstiese waarde dat hulle van geen betekenis is as kleur- of wesensbepalende faktor van Afrikaans nie. Afrikaans het deur-en-deur ' $n$ Germaans-Dietse taal in klankstelsel én struktuur én woordeskat gebly, omdat dit ontwikkel het uit die Nederlands-dialektiese taalvorm van die provinsie Suid-Holland, moontlik, volgens die dialektoloog Kloeke se 
bevinding, uit die van suidelike Suid-Holland, met geringe bymengsels uit ander dialekvorme.

Dit is van belang om in aanmerking te neem dat in hierdie provinsie die groot en belangrike stede geleë is, die sentra waar die aktiwiteite op alle terreine hulle saamgetrek het, bv. Rotterdam, ekonomiese middelpunt van skeepvaart en handel, knooppunt van verkeersweë in alle rigtinge, binnelands sowel as buitelands; Leiden, universiteitstad, geestelike, kulturele middelpunt; Den Haag, setel van Oranjehuis en die Staatsbestuur; Amsterdam-wat ons ook maar feitlik tot die taalgebied van Suid-Holland kan reken-, kernpunt by uitnemendheid van nasionale aktiwiteit in alle vorme: kunste en wetenskap, kerklike en politieke aktiwiteit, brandpunt van die ondernemingsgees in handel en skeepvaart; Dordrecht, kerklike saamtrekpunt, en nog ander stede aan die periferie, soos Utrecht, Middelburg e.a. In die provinsie en stede trek mense uit ander provinsies en dialekstreke saam. Hier bereik die volksaktiwiteit van die Goue Eeu sy kulminasiepunt en straal invloed uit oor heel Nederland. Begryplik moet hier dan ook die sterkste die noodsaaklikheid gevoel word vir 'n algemene gebruiks- en omgangstaal, 'n algemene skryfen literatuur-, kerk- en staatstaal. Maar die noodsaak verhef juis die taal van hierdie provinsie en sy stede tot die ereposisie van mees-gebruiklike aanwending en erkenning as dié volks- en staatstaal, handelstaal, algemene verkeerstaal, die taal van literatuur en prediking-die Algemeen-Beskaafd, saamgetrek in die kultuursentra en sentra van grootste aktiwiteit. En dis hierdie taalvorm wat Jan van Riebeeck in sy memorie aan en korrespondensie met die Here XVII gebesigr het, wat die taal van sy gebed, sy Dagverhaal en sy bestuur aan die Kaap was; dis hierdie taal wat die van die Statebybel, van die liturgiese stukke van Dordt en van die berymde Psalme was. Maar meer: dit het aan die Kaap die offisiële bestuurstaal gebly vir die hele tydperk van die Kompanjiebewind, dit was aldeur die taal van die onderwys, die kerk en prediking, die skryftaal van iedereen en die enigste leestaal. Hier in dic Kaap sluit hierdie twee taalvorme, nl. die dialektiese Suid-Hollands as spreektaal en die Algemeen-Beskaafd wat in en uit die taal van hierdie provinsie en sy stede ontstaan het, bymekaar aan, en uit hierdie taalkompleks het Afrikaans voortgekom: ontstaan uit die dialektiese volkstaal, hoofsaaklik van Suid-Holland, oorgedra in die mond van vreemdelinge maar steeds beskerm, gereguleer, gesuiwer, versterk en gerig deur die geskrewe Hollands, die Algemeen-Beskaafd. So is ons taalerfenis die draer van alles groots en goeds en skoons en verheffends wat die Goue Eeu daarin beliggaan het. 
'n Belangrike faktor wat by hierdie taalwording en taalgebruik in die spel was, was die feit dat die hoë nasionale gespannenheid, taak- en roepingsbewustheid van die Nederlandse volk ook onvermydelik en natuurlik meegebring het taalbewustheid, taaltrots en taalliefde. Trouens, dié gesindheid het hom reeds vroeg in die sestiende eeu geopenbaar as uitvloeisel van die Renaissance en die Humanisme, versterk deur die Reformasie, wat die volkstaal tot sy medium verhef teenoor Latyn, en hierdie gesindheid was deurgaans die stuwende mag, steeds versterk deur allerlei oorweginge en faktore, wat die Nederlandse taal so laat ontwikkel en opgevoer het tot die hoogtes wat dit bereik het byvoorbeeld by Hooft en Vondel en in die Statebybel. En in hierdie opsig is Jan van Riebeeck ook 'n verteenwoordiger van sy tyd-en vir ons daardeur 'n gedenkwaardige erflater. Immers, hy het deur sy beleid Hottentot en slaaf en vreemdeling in sy, poorte die Hollandse taal laat aanleer en steeds oor die bestaan en behoud daarvan gewaak. Uit sy Dagverhaal blyk sy ingenomenheid met die verskynsel dat die Hottentotte so gou en "redelyck fray" die Nederduitse taal aanleer-al is die ingenomenheid ook uit prakties-ekonomiese oorweginge. En toe Van Riebeeck in 1662 sy kommandeurskap moes afsluit, kon hy met voldoening in sy Memorie ter Informatie aan sy opvolger, Wagenaer, die volgende nalaat: „De slaven leeren hier niet als duyts en oock de Hottentoos, sulx hier geen ander tael gesproocken wordt, ende soo in ordre blyvend een fraye sake sal syn, om Portugesen andere altijt stom te doen staen voor dese natie en deselve daer door te min te kunnen verleyden ...." So het Van Riebeeck dan getrouelik uitvoering gegee aan die dekreet van Van Goens van 1657, waarin die invoering en gebruik van Portugees deur die slawe aldus verbied word: „Met de compste van de slaven sal UE. seer sorgvuldigh zijn geen portugeese tael hier in te voeren, maer 'tzelve met alle middelen voor comen .....”, en verder: „ende sal U.E. geen tael als ons moedertael tegens de slaven gebruijcken, en niet gedoogen dat se andere spreecken, dat bij verloop van jaeren gerustheijt sal connen geven".

Die deurvoering van hierdie taalbeleid word 'n kwarteeu later, in 1685, deur Kommissaris-generaal Van Rheede bevestig as hy in 'n verslag getuig dat daar niemand onder die Koloniste is wat Hottentots ken nie, en dat die inlanders die "Nederduydsche spraeck” aanleer en „op haer manieren seer krom en bij nae onverstandelijk spreken". Voorts spreek hy kommer uit oor die verskynsel dat dié kromtaal deur Nederlanders, veral deur hule kinders, oorgeneem word en vrees dat dié kromtaal gevestig sal raak. Die beleid van „vernederduydsching” word ook gevolg t.o.v. die Franse Hugenote van 1688. Ook hulle moes deur omgang met 
Nederlandse Koloniste, deur onderwys en prediking "Nederduits""recht Hollands Nederduyts"-aanleer, en hulle eie taal het in twee geslagte met nalating van die geringste spore uitgesterf. So is dan by alle inwoner- en volksgroepe die Hollands-Nederduitse taalvorm in spraak en skrif gehandhaaf en bestendig. As ons die taalvorm wat die Koloniste met baie min geleerdheid en beperkte skryfbekwaamheid in die agttiende en negentiende eeue gebruik, ondersoek en beoordeel, dan blyk baie duidelik dat ons taal, ons beskawing en ons kultuur, ons lewensaard en lewenshouding ' $n$ erfenis is van Jan van Riebeeck, 'n nalatenskap wat hier uit- en omgebou is tot ons eic Christelik-Afrikaanse, in besonder Calvinisties-Afrikaanse, lewensaard en lewenshouding.

Die erfenis is ons oorgedra, toegedra en ingedra in en met die Hollandse taal, vir meer as twee eeue ons moedertaal. Ons kan Afrikaans nie daarvan losmaak nie, ons kan die Hollandse klankaard, die Hollandse stylaard, die Hollandse taalaard, wat alles die struktuur van Afrikaans bepaal, nie daar uithaal nie maar ewemin die geestelike nalatenskap uit ons wese haal. Deur en met en in en uit die erfenis het ons 'n eie nasie met ' $n$ eie taal, 'n eie lewensaard en lewensvorm gebou. Die wet van die historiese kontinuiteit, van genealogiese afstamming in fisieke sowel as geestelike, kulturele en linguïstiese sin lê op ons die onontwykbare en onontkombare taak om aanvulling, verryking en versterking te soek by die Nederlandse bron. Ons moet woeker met die kapitaal van ons nalatenskap, d.w.s. ons moet wat ons eie is, uitbou en ontwikkel tot die beste, die hoogste, die skoonste en die volkomenste wat ons kan, wetende dat ons op alle terreine die haas onuitputlike Nederlandse bron het om daaruit ons kapitaal aan te vul, uit te brei en die belegging daarvan te versterk en te verstewig: greestelik, wetenskaplik, kultureel, nasionaal of in watter opsig ook al. Maar ons eie wesensaard vereis dat ons selektief sal oorneem, nie somaar onvoorwaardelik net omdat dit die handelsmerk "vervaardigd in Necierland" dra nie maar slegs die dinge wat ons eie sal aanvul, versterk en verryk. Dit sluit nie die moontlikheid en wesenlikheid uit nie dat ons ook versterk en verryk kan word uit die rykdomme van ander kulture. Mar die Nederlandse dra naturrlikerwys en noodwendig ons eerste liefde: ons het daaruit gegroei, dit het ons wordende wese beheers, gerig en bepaal, tredhoudend met die wording van 'n eie taal, en in en deur die taal word ons wese vandag nog deur die erfenis beheers en moet dit onverbiddelik daardeur, getrou in gees en in tradisie, vir die toekoms gerig word.

So word die Jan van Riebeeck-eeufees vir ons 'n geestelike versterking maar moet dit ook wees 'n Airikaans-Hollands-nasionale versterking in historiese sin.

F. J LABUSCHAGNE. 